Studia z Dziejów Średniowiecza nr 21, 2017

\author{
Rafał Kubicki
}

(Gdańsk)

\title{
Dokument potwierdzajacy zawarcie umowy franciszkanów z władzami miasta Braniewa w 1301 r. w sprawie zmiany lokalizacji klasztoru
}

Key words: Order of Friars Minor (Franciscans), medieval Prussia, Braniewo (Braunsberg), Teutonic Order

Studia nad działalnością zakonu franciszkanów w Prusach Krzyżackich mają już długą tradycję, a ich efektem są liczne opracowania i edycje źródeł do dziejów prowincji saskiej zakonu w średniowieczu ogłoszone przez Leonharda Lemmensa ${ }^{1}$. Na ich podstawie przede wszystkim powstała synteza Wernera Rotha, dotycząca działalności dominikanów i franciszkanów w państwie zakonu krzyżackiego w Prusach do 1466 r. $^{2}$ Prace L. Lemmensa sa również podstawą współcześnie powstających opracowań ${ }^{3}$. W związku z tym trzeba

1 Urkundenbuch des alten sächsischen Franziskanerprovinzen, Bd. I: Die Observantenkustodie Livland und Preussen; Bd. II: Die Kustodie Preussen [dalej: USF II], hg. v. L. Lemmens, Düsseldorf 1913; L. Lemmens, Aus der Geschichte der deutschen Franziskaner im Ordenslande Preußen, „Mitteilungen des Coppernicus-Vereins für Wissenschaft und Kunst zu Thorn" [dalej: MCV] 1912, H. 20, s. 58-64; idem, Zu den Anfängen der Franziskanerklöster im Ordenslande, MCV, 1913, H. 21, s. 2-8; idem, Die Franziskanerkustodie Livland und Preussen. Beitrag zur Kirchengeschichte der Gebiete des Deutschen Ordens, Düsseldorf 1912; idem, Aus ungedruckten Franziskanerbriefen des XVI. Jahrhunderts, Aschendorff 1911; idem, Briefe und Urkunden des XVI. Jahrhunderts zur Geschichte der sächsischen Franziskaner, „Beiträge zur Geschichte sächsischen Franziskanerprovinz" 1911/1912, Bd. 4/5, s. 43-100.

2 W. Roth, Die Dominikaner und Franziskaner im Deutsch-Ordensland Preußen bis zum Jahre 1466, Königsberg 1918.

3 J. Sarnowsky, Die Dominikaner und Franziskaner im Ordensland Preußen [w:] Franciscan Organisation in the Mendicant Context. Formal and informal structures of the friars" lives and ministry in the Middle Ages, eds. M. Robson, J. Röhrkasten, 
przypomnieć, iż poza studiami L. Lemmensa i W. Rotha, w 1930 r. ukazał się jeszcze drobny przyczynek dotyczący dziejów klasztoru franciszkanów w Braniewie, którego autorem był Eugen Brachvogel ${ }^{4}$. Dotyczył omówienia treści niepublikowanego w zbiorze L. Lemmensa i pominiętego przez wydawców dyplomatariusza warmińskiego, dokumentu ugody franciszkanów braniewskich z władzami miasta z 28 kwietnia 1301 r. w sprawie zmiany lokalizacji klasztoru. Niestety, autor przyczynku nie zamieścił edycji tego ciekawego przekazu. W związku ze znaczeniem wspomnianego dokumentu, nie tylko dla historii klasztoru braci mniejszych w Braniewie, publikujemy jego treść w oparciu o zachowany odpis, na który powoływał się w swym omówieniu E. Brachvogel.

Dokument ten znany jest jedynie z kopii sporządzonej pod koniec XVI w. i przechowywanej dawniej w Archiwum Państwowym w Królewcu (zespół Etats-Ministerium), a obecnie w Tajnym Archiwum Państwowym Pruskich Dóbr Kultury w Berlinie-Dahlem (Geheimes Staatsarchiv Preussischer Kulturbesitz). Znaczenie tego dokumentu podnosi lista świadków potwierdzających zawartą ugodę, wśród których byli liczni dostojnicy krzyżaccy, mieszczanie elbląscy i przełożeni klasztorów franciszkańskich w Prusach.

Jak skonstatował E. Brachvogel, dokument ten rozjaśnił wcześniej niezrozumiały dla historyków (Franz Hipler, Leonharda Lemmens, Werner Roth) przebieg sporu władz miasta z franciszkanami w Braniewie oraz problem kolejnych lokalizacji klasztoru ${ }^{5}$. Przedstawiając sprawę w wielkim skrócie: franciszkanie znaleźli się w Braniewie za sprawa biskupa warmińskiego Henryka I Fleminga w 1296 r. ${ }^{6}$ Niestety, nie wiadomo, gdzie znajdowała się ich pierwsza siedziba ${ }^{7}$.

Berlin 2010 (,Vita Regularis Ordnungen und Deutungen religiosen Lebens im Mittelalter", Bd. 44), s. 43-64; S. Zonenberg, Die Beziehungen zwischen dem Deutschen Orden und den Franziskanern in Preußen bis zum Jahre 1466 [w:] Leben zwischen und mit den Kulturen. Studien zu Recht, Bildung und Herrschaft in Mitteleuropa, hg. v. R. Skowrońska, H. Flechenecker, Toruń 2015 („Studienreihe der polnischen historischen Mission”, Bd. 2), s. 69-113.

4 E. Brachvogel, Die Vorgeschichte des Franziskanerklosters in Braunsberg, „Zeitschrift für die Geschichte und Altertumskunde Ermlands” 1932, Bd. 24, H. 1-3, s. 523-527.

5 F. Hipler, Die ehemalige St. Marienkirche der Franziskaner in Braunsberg, „Pastoralblatt für die Diözese Ermland” 1883, H. 15, nr 1, s. 3-4.

6 USF II, nr 405.

7 L. Lemmens, Zu den Anfängen..., s. 7-8; W. Roth, Die Dominikaner..., s. 139; S. Zonenberg, Die Beziehungen..., s. 89-90. 
W 1297 r. kapituła prowincjalna zakonu w Erfurcie podjęła decyzję o przyjęciu klasztoru do prowincji saskiej ${ }^{8}$. Kilka lat później wybuchł spór klasztoru z władzami miasta. Mieszczanie Braniewa odwoływali się do zagwarantowanego im w przywileju lokacyjnym miasta z $1280 \mathrm{r}$. zakazu zakładania w jego obrębie, bez woli i zgody mieszczan, wszelkich wspólnot klasztornych ${ }^{9}$. Dążąc do zażegnania sporu w dniu 14 kwietnia 1301 r. na zamku krzyżackim w Elblagu, w obecności biskupa warmińskiego Eberharda i mistrza krajowego zakonu krzyżackiego Helwiga von Goldbach, i 20 kwietnia tego samego roku przed biskupem Eberhardem w Braniewie, toczyły się w tej sprawie negocjacje. Spór mieli rozstrzygnać początkowo powołani przez obie strony sędziowie rozjemczy, ostatecznie jednak ze względu na brak porozumienia między nimi, rozsądził go biskup warmiński. Zgodnie z treścią zawartego porozumienia, spisanego 28 kwietnia 1301 r. na zamku w Braniewie przez notariusza biskupiego mistrza Jana z Zantyru, franciszkanie oddali działkę w mieście, jednocześnie rezygnując z dochodzenia do niej wszelkich praw, a w zamian otrzymali od miasta inna, położoną na północ od niego, przy rzece Pasłęce. Od wschodu graniczyła z brzegiem Pasłęki, a od południa z fosa miejska. Ponadto ustalono, że miasto miało zbudować bramę i most przez fosę miejska, który łączyłby działkę klasztorna z miastem. W związku z tym sporem powstała też tradycja o rzekomo nielegalnym zniszczeniu w mieście klasztoru franciszkanów przez mieszczan lub Krzyżaków ${ }^{10}$. Podjęte w 1301 r. decyzje nie okazały się jednak trwałe i dopiero trzecia lokalizacja klasztoru była ostateczna. W dniu 20 lutego 1330 r. potwierdzono, że konwent franciszkanów został przeniesiony z powrotem do miasta. Decyzję tę podjęto ze względu na zagrożenie, jakie mogłoby stwarzać opanowanie jego obiektów przez wrogie oddziały próbujące szturmować miasto ${ }^{11}$. W tym miejscu klasztor istniał do połowy XVI w., by potem przejść w ręce kolegium jezuitów.

8 USF II, nr 405; W. Roth, Die Dominikaner..., s. 140.

9 Codex Diplomaticus Warmiensis oder Regesten und Urkunden zur Geschichte Ermlands, Bd. I [dalej: CDW I], hg. v. C.P. Woelky, J.M. Saage, Mainz 1860, nr 56, s. 100.

10 Do wcześniejszego sporu nawiązał w 1310 r. papież Klemens V, wspominając o zniszczeniu siedziby franciszkanów w Braniewie: „Eisdem fratribus minoribus se dicto loco ignominiose eiecti, eundem locum funditus destruxerunt”, zob. USF II, nr 408. Papież wskazywał na Krzyżaków jako sprawców konfliktu. Późniejsi kronikarze pruscy widzieli ich natomiast w mieszczanach Braniewa, zob. L. Lemmens, $Z u$ den Anfängen..., s. 7.

11 USF II, nr 417; W. Roth, Die Dominikaner..., s. 141. 
W edycji zachowano zasadniczo oryginalną pisownię przekazana w odpisie. Ujednolicono jedynie pisownię wyrazów wielką litera, ograniczajac ją do nazw własnych i nazw miesięcy. Kursywą oznaczono rozwiązane abrewiacje. Dane dotyczące identyfikacji osób występujących w dokumencie oparto w większości na ustaleniach E. Brachvogela.

\section{Dokument}

Braniewo, 28 IV 1301

Biskup warmiński Eberhard i mistrz krajowy zakonu krzyżackiego w Prusach Helwig von Goldbach potwierdzaja umowę wynegocjowana pomiędzy mieszczanami Braniewa i kustoszem franciszkanów w Prusach Janem oraz jego braćmi zakonnymi, w trakcie spotkań przed biskupem i mistrzem krajowym na zamku krzyżackim w Elblagu 14 IV i przed biskupem $w$ Braniewie 20 IV. Obie strony powołały sędziów rozjemczych, ponieważ jednak nie mogli oni dojść do porozumienia, ostatecznie sprawę rozsqdzit biskup warmiński. Zgodnie z tym franciszkanie odstęuja dziatke nadana im przez biskupa Henryka Fleminga [ $w 1296 r$.] $w$ zamian otrzymuja inna, położona poza miastem nad rzeka Pastęka. Obie strony określaja szczegółowo swe zobowiazania: franciszkanie rezygnuja $z$ dochodzenia praw do dziatki nadanej przez biskupa a mieszczanie zobowiqzuje się do wybudowania bramy $i$ mostu, taczacego dziatke klasztorna z miastem.

Oryg.: brak.

Odpis: XVI w., GSPK, EM 31 b 2, Nr. 55, k. 15r-16v.

Wzm.: E. Brachvogel, Die Vorgeschichte des Franziskanerklosters, s. $523-527$.

Uwaga: karty papierowe o wym. 200,2 $\times 343,1 \mathrm{~mm}$, ze znakiem wodnym, foliacja wykonana za pomoca stempla.

${ }^{a}$-Litterae resignationis primae areae fratrum minorum Brunsbergensis quae ante extra civitatis habuerunt ${ }^{-a}$

In nomine Domini Amen. Nos Eberhardus ${ }^{1}$ Dei gratia episcopus Varmiensis ecclesiae et frater Heluicus dictus de Goltbach magister ordinis Hospitalis Sanctae Mariae Hierosolomitani per Prussiam ${ }^{2}$ ommnibus Christi fidelibus praesentes literas uisuris salutem 
et cognitionem omnium subscriptorum. Quam salutiferis moneamur consiliis gratia pacis et patientiae munitos nos ostendere, non solum sapiens sed et canonum docet authoritas, dicens: Non enim nisi tempore pacis bene colitur pacis author. Hortatur etiam nos Apostolus dicens: Si fieri potest quantum in nobis est pacem tenentes ad omnes ${ }^{3}$. Coram nobis igitur, ut amicabilibus compositionibus de uoluntate partium et assensu, anno ab incarnatione Domini $\mathrm{M}^{\circ} \mathrm{C}^{\circ} \mathrm{C}^{\circ} \mathrm{C}^{\circ}$ primo, in die quartodecimo, in mense Aprilli ${ }^{4}$, in castro in Elbingo ${ }^{5}$ et domo nostra scilicet magistri supra dicti praesentibus quibusdam nostris fratribus ac aliis tam clericis quam laicis pluribus fide dignis super quibusdam discordiis ac controversiis habitis inter fratrem Joannem custodem ordinis minorum fratrum per Prussiam ${ }^{6}$ suosque fratres ex una parte nec non ciues et ciuitatem in Brunsberc ${ }^{7}$ ex altera. Primo a parte custodis et suorum fratrum quaedam molestiae et iniuriae fuerunt propositae demum etiam ciuibus dictae ciuitatis pro se suas quasdam molestias et iniurias proponentibus, quibus utrobique auditis maturo sapientum habito consilio et secuto. Cum dicti fratres minores in ciuitate Brusberc quandam tenerent aream, quam sibi asserebant data $m$ a uenerabili patre domino Henrico felicis memoriae episcopo ${ }^{\mathrm{b}-}$ ecclesiae $^{-\mathrm{b}}$ Varmiensis $^{8}$ de qua area dicti ciues affirmabant, quod in priuilegiis ciuitatis suae et libertatibus donatis a domino et praedicti venerabili Henrico bonae memoriae episcopo Varmiensis continetur, quod eadem area de proprietate ciuitatis et ciuium sit, et quod eadem ciuitas continuere retroactis temporibus possedisset, in qua etiam area dicti fratres minores modicum commodum propter eius artitudinem habere poterant, qua etiam area ciuitas carere non poterat, quod a quibusdam expertis, quibus de ipsa constabat area dicebatur ad hoc ut dictus custos cum suis fratribus pacifice ac uoluntarie omni iuri si quod habere uidetur ac omni disceptationi desisteret, dicti ciues promiserunt supradictis fratribus minoribus extra ciuitatem Brunsberc ad plagam angulonis, aliam competente $m$ aream se daturos, de qua ratione coram nobis custos dictus cum suis fratribus fuit pro bono pacis et concordiae sic contentus, ut sicut ipse cum suis fratribus, sic et ciues in totum, ut infra dicetur, cederent accessioni. Duodecimo itaque kalendas Maii ${ }^{9}$ dictus frater Joannes custos pro se et suis fratribus, cum fratre Bertoldo gardiano ${ }^{10}[\mathrm{k} .15 \mathrm{v}]$ gardiano [!] in Culmiensis veniens in Brunsberc. Coram nobis Eberhardo dei gratia episcopo Varmiensis ecclesiae habitis una cum praedictis ciuibus diuersis tractatibus in hoc ex utraque parte contenti finaliter resederunt quod praedicti ciues custodi et suis fratribus extra 
ciuitatem ad angulonem ut praedictam aream in descensu aquae Passeriae ${ }^{11}$ assignarunt. In latitudine habentem decem et octo uirgas, quae messeruten ${ }^{12}$ vulgariter appellantur. In longitudine uero uiginti uirgas et sex ulnas habentem. Termini autem dictae areae distinguuntur taliter quod inter praedictam aream et ipsius quatuor latera, uidelicet orientale in descensu aquae Passeriae meridianum circa fossata ciuitatis et occidentale ac septentrionale debeant esse com$m$ unes stratae pro utilitate transeuntium ac omnium libertate. Ita tamen quod spacium quod est intra claustri et Passeriam omnibus sit commune sicut et uiae aliae circunquaque huius autem areae in quatuor finibus siue proncipiis laterum iuxta mensuram praehabitam signa ad uoluntatem partium sunt in fixa in nostra praesentia, de qua limitatione contentabatur in nostra praesentia pars utraque. Quicquid etiam extra mensuram dictae areae relinquit totum utilitati ciuitatis ac ciuium deputatur dicti insuper ciues portam et pontem, in quo currus transire poterint per fossata construent uersus dictorum fratrum aream inter domum Hermanni de Hunthoubit ${ }^{13}$ et Henrici Rurmunt ${ }^{14}$, quia ibi utrique parti conuenientius uidebatur, adiectum etia $m$ fuit coram nobis, quod si ciuitas Brunsberc ad locum transponeretur aliud in posterum ex tunc si tempore transpositionis dicta fratrum claustri area esset inter ciuitatem, tunc ipsis fratribus daretur, area pro claustro inter ciuitatem secundum pro tunc inter eos et ciues conuenerit. Si uero fuerit extra ciuitatem dicta fratrum area, tunc extra ciuitatem in priori latitudine et longitudine ipsis debebit pro claustro area assignari secundum pro tunc fratribus minoribus et ciuibus competere dinoscetur. Insuper ad omnem amfractum litis remouendum dictus custos Prussiae nomine suo et omnium fratrum ordinis sui omni iuri, quod habere uidebatur de prima area in ciuitate per licentias concessionis, donationis et quouis alio modo seu titulo, liberare ac spontanere cessit, et in manus nostras totaliter et ex integro resignauit, ita ut utraque pars renunciauit omni iuri, accessioni, subsidio dolo malo et licentiis inter partes super ipsa area habitis seu habendis in perpetuum, a Sede Apostolica, uel ab aliis principibus aut praelatis appellationi, relationi, omnique auxilio iuris canonici et ciuili, quod sibi in parte, uel in totum tam pro principalibus personis quam inferioribus competere uideretur promittebat etiam utraque pars coram nobis, nec per se nec per alias in perpetuum questionem aut controuersia $m$ propter dictas discordias aut annexos articulos parti alterutri se moturam. Placuit insuper dictis partibus in totum pro se et suis membris [k. 16r] suis membris in quasdam 
dictas personas uidelicet arbitros infra scriptos compromittere. Forma uero electionis personarum compromissionis talis est, ut in sequentibus continetur dominus frater Joannes custos dictus et frater Bertoldus gardianus Culmensis, cum aliis duobus fratribus, pro se et omnibus suis fratribus sponte ac maturo consilio elegerunt fratrem Henricum commendatorem de Balga ${ }^{15}$, fratrem Conradum Sueuum in Elbingo ${ }^{16}$, Theodoricum militem dictum de Ulsen $n^{17}$ et Hermannum scultetum de Elbingo ${ }^{18}$. Ciues vero similiter uoluntate spontanea et maturo consilio elegerunt pro se fratrem Bertoldum commendatorem in Kungesberc ${ }^{19}$, fratrem Cunradum de Lichtenhain commendatorem in Elbingo ${ }^{20}$ et Hertuicum de $\mathrm{Hu} / \mathrm{me} / \mathrm{l}^{21}$ et Peregrinum ${ }^{22}$ ciues in Elbingo ad sopiendas inter dictas partes omnes discordias damna, iniurias, offensas, controuersias et quicunque amfractus, discordiae inter ipsas partes dinoscitur extitisse, sic quod utraque pars in totum per conditiones paulo ante propositas ipsis arbitris omnia sua negocia beniuole committebant, ut quicquid dicti arbitri, pro bono pacis et concordiae inter partes diffinirent, deberet in perpetuu $m$ sub poena apposita inuiolabiliter obseruari. Si tamen dicti arbitri in vnam non possent concordare sententiam, extunc dominus venerabilis Eberhardus Varmiensis episcopus assumetur a dictis arbitris, et cuius partis consenserit rationabilis illius sententia per conditionem poenae prius propositam ab arbitris inuiolabiliter seruaretur hiis itaque actis testes, qui tunc presentes aderant adhiberi volumus dominum et fratre $m$ ducem de Brunswic ${ }^{23}$, fratrem Eberhardum commendatorem de Marienburc ${ }^{24}$, fratrem Ludouicum de Libentzolle commendatorem in Ragonito ${ }^{25}$, fratrem Eberhardum commendatorem domus in Elbingo ${ }^{26}$, fratrem Cunradum Sueuum, fratrem Henricum dictum de Gerra socium domini magistri ${ }^{27}$, dominum Henricum plebanum in Elbingo ${ }^{28}$, dominos Hermannum ${ }^{29}$ et Bartholomaeum ${ }^{30}$ canonicos Varmiensis ac omnes consules Elbingenses, aliosque quam plurimos fide dignos, ut autem haec ordinatio, atque in arbitros compromissio, simulque causae decisio in perpetuum rata, firma, inuiolabiliter perseuerent, et ne quos in posterum aliqua, quae in ipsa paccione posita non fuerant, acceptare ualeat presentes litteras muniri fecimus sigillis nostris uidelicet sigillo Eberhardi Dei gratia Varmensis episcopi, fratris Heluici dicti de Goltbach magistri ordinis hospitalis S. Mariae Hierosolomitani per Prussiam, sigillo capituli Varmiensis ecclesiae, sigillo fratris Eberhardi commendatoris in castro Margenburc, sigillo fratris Ludouici commendatoris in Ragonita, sigillo fratris Joannis custodis ordinis minorum per Prussiam, sigillo conuentus fratrum 
minorum in Thorn, sigillo conuentus in Culmine minorum fratrum et fratris Bertoldi gardiani ibidem, sigillo conuentus minorum de Noue $^{31}$, sigillo conuentus minorum in Brinsberc, nec non sigillo ciuitatis de Brunsberc, in robur firmissimum et munimen datum per manus cappellani nostri magistri Joannis [k. 16r] magistri Joannis de Zantir ${ }^{32}$. Actum ut sub dicitur anno Domini MCCC primo quarto kalendas Maii ${ }^{33}$. In Brunsberc in castro Ecclesiae Varmiensis.

a-a Tekst nagłówka napisany kursywa inna ręka niż dalszy odpis.

b-b Tekst nadpisany.

1 Eberhard z Nysy, biskup warminski w latach 1300-1326.

2 Helwig von Goldbach, mistrz krajowy zakonu krzyżackiego w Prusach 26 III 1301-30 III 1302 r.

${ }_{3}$ Pismo Święte, List św. Pawła do Rzymian 12,18.

414 IV $1300 \mathrm{r}$.

5 Zamek krzyżacki w Elblagu.

${ }^{6}$ Jan, kustosz kustodii pruskiej franciszkanów, wzmiankowany tylko $w$ tym dokumencie.

7 Miasto Braniewo.

8 Mowa o nadaniu dokonanym w 1296 r. przez biskupa warmińskiego Henryk Fleming (1278-1300), USF II, nr 405, s. 111; L. Lemmens, Zu den Anfängen..., s. 7.

912 kalendy maja $=20$ kwietnia.

10 Bertold gwardian klasztoru franciszkanów w Chetmnie, wzmiankowany tylko w tym dokumencie.

11 Rzeka Pastęka (niem. Passarge) przeptywa przez Braniewo.

12 Pręt, jednostka dtugości wynoszaca 4,32 m, zob. W. Odyniec, Chetmiński system miar $i$ chetmińska stopa mennicza $w$ rozwoju historycznym [w:] Studia Culmensia historico-juridica, czyli Ksiega pamiatkowa 750-lecia prawa chetmińskiego, red. Z. Zdrójkowski, t. 1, Toruń 1990, s. 398.

${ }_{13}$ Herman de Hunthoubit, bliżej nieznany mieszczanin z Braniewa.

${ }^{14}$ Henryk Rurmunt, bliżej nieznany mieszczanin z Braniewa.

15 Henryk von Isenberg, komtur w Batdze w latach 1300-1312 i w 1315 r.

${ }_{16}$ Konrad Schwabe, wzmiankowany jako komtur domowy w Elblagu $w$ latach 1287, 1288, 1290.

17 Rycerz Teodoryk de Ulsen, właściciel w Jędrychowie (Heinrichsdorf) $i$ Wtóczyskach (Vierzighuben), wzmiankowany w latach 1296-1319, CDW I, nr 96, 99, 103, 105, 121, 124, 138, 157, 166, 168, 171, 173, 190.

18 Herman, sottys dziedziczny $w$ Elblagu, wzmiankowany ponadto $w$ latach 1282-1287, zob. R. Czaja, Urzędnicy miejscy Elblaga do 1524 roku, Elblag 2010, s. 179.

19 Bertold von Brühaven, komtur w Królewcu w latach 1289-1302.

${ }_{20}$ Konrad de Lichteihein, komtur w Elblagu 5 III 1300-15 III 1303 r.

21 Hartwig de Hu[me]la, mieszczanin w Elblagu, wzmiankowany w latach 1284 i 1286 .

22 Peregryn, mieszczanin z Elblaga. Wzmiankowany w 1287 r. właściciel dóbr $w$ Beberhof, Kalenberg i Pielgrzymowie (Pilgramsdorf), CDW I, s. 128-129, 138, 140, 144, 146, 215. 
${ }^{23}$ Luther von Braunschweig, pochodzqcy z rodziny ksiażęcej, późniejszy wielki mistrz zakonu krzyżackiego w latach 1331-1335.

${ }^{24}$ Eberhard von Virneburg, komtur w Malborku w latach 1298-1304 r.

${ }_{25}$ Ludwik de Libentzell, komtur w Ragnecie w latach 1294-1300.

${ }_{26}$ Eberhard, komtur domowy w Elblagu, jako komtur domowy wzmiankowany tylko w tym dokumencie. W 1290 r. w Elblagu byt kompan o imieniu Eberhard.

${ }^{27}$ Henryk de Gera, kompan wielkiego mistrza, komtur $w$ Elblagu $w$ latach 1304-1312i $w 1315 r$.

${ }^{28}$ Henryk, pleban w Elblagu w latach 1297-1303, zob. M. Toeppen, Elbinger Antiquitäten. Ein Beitrag zur Geschichte des städtischen Lebens im Mittelalter, H. 2, Danzig 1872, s. 109.

${ }_{29}$ Herman, kanonik warmiński, wzmiankowany w latach 1278-1322, zob. R. Krajniak, $Z$ badań nad biografiami członków warmińskiej kapituły katedralnej w pierwszym okresie jej funkcjonowania (do połowy XIV wieku), ZH 2015, 80, z. 1, s. 80-81.

${ }^{30}$ Bartłomiej, kanonik warmiński, wzmiankowany w latach 1297 i 1301, CDW I, $\operatorname{nr} 99,111$.

31 Miasto Nowe nad Wista.

32 Jan z Zantyru, kapelan i notariusz biskupa warmińskiego Eberharda, wzmiankowany w 1325 r., CDW I, nr 220.

334 kalendy maja $=28$ kwietnia.

\section{Abstract \\ The Document Confirming the Agreement between the Fran- ciscans and the City of Braniewo from 1301 Regarding the Changing of the Monastery's Location}

The subject of this study is the agreement between the Franciscans and the City of Braniewo from April 28, 1301, regarding the changing of the location of the monastery which was hitherto known only from the study by Eugen Brachvogel. Leonhard Lemmens's register of sources on the history of the old Saxon province of the Franciscans and the Warmian Diplomatic Codex both fail to mention it. Today, the contents of the document are known from the copy drawn up at the end of the $16^{\text {th }}$ century and currently stored in the Etats-Ministerium collection in the Prussian Privy State Archives in Berlin-Dahlem (Geheimes Staatsarchiv Preussischer Kulturbesitz).

The document provides important information helpful in reconstructing the dispute between the city and the Franciscans as well as in identifying the subsequent locations of the monastery. The Franciscans came to Braniewo due to the activities of the Warmian bishop Henry I Fleming in 1296. Several years later, a conflict arose between the monastery and the city. On April 14 in Elblag and April 20, 1301, in Braniewo, negotiations were held to resolve the matter. According to the agreement, the 
Franciscans gave up a parcel in the city and in return received another one, located north from the city, near the river Pasłęka. It was decided, moreover, that the city would build a gate and a bridge above the moat which would connect the monastery with the city.

The dispute between the city and the Franciscans also became the source of the legend about the allegedly illegal destruction of the monastery in the city by the citizens or the Teutonic Order. The 1301 agreement turned out to be short-lived and only the third location of the monastery proved to be the final one. On February 20, 1330, it was confirmed that the Franciscan monastery was moved back to the city. This decision was made due to the danger it would pose if its edifices were seized by enemy forces attempting to storm the city. 